\title{
SYNOPSIS
}

News

$\bullet$

AnALYSIS

- Practice

WAITINg Times

\section{Crisis in orthopedic care: surgeon and resource shortage}

A national shortage of at least 400 orthopedic surgeons is compounded by greater demand from an aging population and a "critical" lack of orthopedic resources, such as operating room time, that is steadily worsening, concludes a Canadian Orthopaedic Association (COA) study.

The national median waiting time from referral to treatment by an orthopedic surgeon increased $65 \%$ between 1993 and 2003 , from 19.5 weeks to 32.2 weeks.

According to the report, Canada is nearly last among Western nations in terms of the number of orthopedic surgeons per population (3.1 per 100 000). In 2002, there were 1126 orthopedic surgeons practising in Canada. Each year, about 45 new orthopedic surgeons graduate and another 9 immigrate. However, an average of 28 orthopedic surgeons leave Canada, often due to a lack of access for their patients. In addition, about 35 reach retirement age each year. The end result is a net decrease of 9 orthopedic surgeons annually.

"To serve the population needs, an additional 400 orthopaedic surgeons are needed immediately in Canada with sufficient resources to practice at a full time equivalent level," concludes the report.

Restricted operating-room time means less than half of Canada's practicing orthopedic surgeons work at full capacity. Inadequate budgets to purchase joint implants and instruments means that Canadian hospitals are often forced to limit the number of orthopedic procedures performed annually, leading to lengthy waiting times and surgery backlogs.

Last year, orthopedic surgery had the longest waiting time among surgical specialties - a median of 32.2 weeks - between referral and treatment.

This situation is bound to worsen "due to existing unmet need for orthopaedic services, ageing of the population, increasing indications for orthopaedic procedures and ageing of the orthopaedic workforce," states the document. Over 5000 additional operating hours per 100000 population per year are required to adequately service the Canadian population, concludes the COA.

"Even with more surgeons and access to operating resources, it will take some time to clear up the backlog of bone and joint surgeries so that Canadians waiting for surgery today can return to pain-free, productive lives," said COA President Dr. Robert Hollinshead.

In the long term, more orthopedic surgeons must be trained here. "Even if residency positions were doubled immediately, the need for surgeons now would not be met for over 20 years," states the report.

The COA study echoes warnings of a pending national crisis in a recent BC study that called for $\$ 1.1$ billion to meet the demand for hip and knee replacements by 2008. Knee surgery demand is expected to increase $81 \%$, hip replacements by $36 \%$ in 4 years, according to the BC Orthopaedic Society and the Arthritis Society of BC study. To meet this demand, spending must increase from $\$ 63$ million annually to $\$ 185$ million by 2008 .

COA CEO Doug Thomson, told CMAJ that Canada needs a strategy that includes national standards to ensure wait times for orthopedic patients in the "have-" and "havenot" provinces are not as disparate as they are now.

The median wait to receive treatment after an appointment with an orthopedic surgeon ranged from 10.7 weeks in New Brunswick to 53.4 weeks in Saskatchewan.

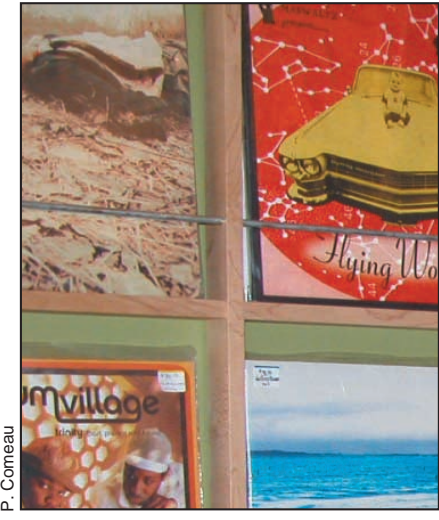

In the past 8 years, Ursula Gort, 74, of Toronto, has had 2 hip replacements and a right shoulder replacement. She waited only 3 months for the hip replacements in 1996 and 2003 but the shoulder was another story. The waiting list was 8 months. "The pain was horrible," she says. "It was a constant nagging pain." She finally had the operation in March.
The crisis in joint replacement demand was underscored when the COA (and the CMA) appeared as interveners in the Supreme Court on June 8 (CMA7 2004;171[2]:122). Dr. Jacques Chaoulli, a family physician in Montréal, and patient George Zeliotis argued for the right to purchase private medical insurance to receive medical treatment more quickly. Zeliotis waited more than a year for a new hip in 1997. A ruling is expected on the case in the fall.

The COA believes the case fuels its call for a national plan. -Pauline Comeau, Ottawa 